\title{
O PAPEL DOS MEDICAMENTOS NO CONTROLE DA CARGA VIRAL E DE CÉLULAS CD4 EM PACIENTES COM HIV DE UMA CIDADE DO MEIO- OESTE DE SANTA CATARINA
}

\author{
THE ROLE OF MEDICINES IN THE CONTROL OF VIRAL LOAD AND CD4 CELLS IN \\ HIV PATIENTS IN A CITY IN THE MIDDLE WEST OF SANTA CATARINA
}

\author{
Vilmair Zancanaro ${ }^{1}$ \\ Mayara Bordignon ${ }^{2}$ \\ Jayna Hüntermann ${ }^{3}$ \\ Emyr Hiago Bellaver ${ }^{4}$
}

\begin{abstract}
Resumo: O Vírus da Imunodeficiência Humana (HIV), agente etiológico responsável pela Síndrome da Imunodeficiência Adquirida (AIDS), é de ampla distribuição e instala-se nos linfócitos, causando alterações no sistema imunológico. Contagens de células $T C D 4^{+}$e carga viral (CV) servem como parâmetros para monitorar a saúde dos pacientes que utilizam a terapia antirretroviral (TARV). O estudo objetivou elucidar o papel dos medicamentos no controle da CV e na contagem de células TCD4+, comparando os resultados antes e depois do início da TARV, entre 2011-2014. Ao todo 10 laudos cedidos pela Vigilância Epidemiológica de uma cidade do Meio - Oeste de Santa Catarina foram avaliados para obtenção dos dados, caracterizando esta uma pesquisa aplicada. Houve prevalência de $70 \%$ de contaminação no sexo feminino entre 38-48 anos. O tratamento de primeira linha foi à dose tripla combinada: Tenofovir (300 mg), Lamivudina (300 mg) e Efavirenz (600 mg). Apesar da diminuição do número de doses e comprimidos, a adesão aos antirretrovirais (ARV), ainda, representa um grande obstáculo a ser superado dentro da farmacologia. Observou-se, também, que pessoas em uso da TARV mantêm contagens de TCD4+ acima de 500 células $/ \mathrm{mm}^{3}$ e CV indetectável, conseguindo levar uma vida normal com expectativa semelhante à da população em geral.

Palavras-chave: HIV; carga viral; CD4; terapia antirretroviral.
\end{abstract}

\begin{abstract}
The Human Immunodeficiency Virus (HIV), etiological agent responsible for the Acquired Immunodeficiency Syndrome (AIDS) is widespread and settles in lymphocytes, provoking changes in the immune system. Counting TCD4+ cells and viral load is a useful parameter to monitor the health of patients who use the Antiretroviral Therapy (ART). The goal of this research was to clarify the role of medicines in viral load control and in the counting of $T C D 4^{+}$cells, comparing the results before and after the beginning of ART use, between 2011-2014. A total of 10 reports given by the Epidemiological Surveillance of a city in the middle west of Santa Catarina were analyzed for data collection, characterizing this as an applied research. There was a prevalence of $70 \%$ contamination in women between 38-48 years old. The first treatment was a combined dose of Tenofovir (300 mg), Lamivudine (300 mg) and Efavirenz (600 mg). Despite the reduction in the number of dosages and pills, the adherence to antiretrovirals is still a big obstacle to be overcome in Pharmacology. It was also noticed that people using ART keep the TCD $4^{+}$counting above 500 cells $/ \mathrm{mm} 3$

\footnotetext{
1 Professora do Curso de Farmácia - Universidade Alto Vale do Rio do Peixe - UNIARP, SC, Brasil. E-mail: vilmair@uniarp.edu.br.

2 Acadêmica do Curso de Farmácia - Universidade Alto Vale do Rio do Peixe - UNIARP, SC, Brasil. E-mail: mayara_bordignon@msn.com.

${ }^{3}$ Acadêmica do Curso de Farmácia - Universidade Alto Vale do Rio do Peixe - UNIARP, SC, Brasil. E-mail: jaynah_26@hotmail.com.

4 Professor do Curso de Farmácia - Universidade Alto Vale do Rio do Peixe - UNIARP, SC, Brasil. E-mail: hi.agobellaver@hotmail.com.
} 
and an undetectable viral load, being able to have a normal live with a life expectancy as high as the average population.

Keywords: HIV; viral load; CD4; antiretroviral therapy.

\section{INTRODUÇÃO}

O HIV, isolado primeiramente em 1983, é um retrovírus com genoma RNA, da Família Retroviridae e subfamília Lentiviridae. Pertence ao grupo dos retrovírus citopáticos e não-oncogênicos que necessita, para multiplicar-se, de uma enzima denominada transcriptase reversa, responsável pela transcrição do RNA viral para uma cópia DNA, que pode, então, integrar-se ao genoma do hospedeiro (SILVA, 2008).

O curso da infecção pelo HIV-1 é caracterizado por uma viremia bifásica, marcada por uma disseminação e propagação do vírus nos tecidos linfáticos, durante a infecção primária, seguida do início da resposta imune antiviral do hospedeiro (FINAZZO, 2012).

O diagnóstico da infecção pelo HIV tem implicações médicas, psicológicas e sociais significativas, impondo esforços adaptativos relevantes às pessoas soropositivas. Ainda sem cura, a AIDS, hoje, tem tratamento e possibilidades efetivas de controle, o que traz novos desafios para os pacientes e profissionais de saúde que trabalham nessa área (SEIDL; ZANNON; TRÓCCOLI, 2005)

No Brasil, o indivíduo diagnosticado como soropositivo para o HIV é submetido, inicialmente, à avaliação laboratorial para determinar seu estado imunológico. Solicitamse exames de linfometria $\mathrm{TCD}^{+}$e a quantificação do RNA (carga viral). Consultas regulares são realizadas para monitorar a evolução clínica do paciente por meio desses exames, que são repetidos três a quatro vezes por ano, segundo preconizadas pelo Ministério da Saúde. O acompanhamento médico da infecção pelo HIV é essencial tanto para quem não apresenta sintomas, quanto para quem já exibe algum sinal da doença (SOUSA, 2014).

A contagem de células TCD4+ em sangue periférico tem implicações prognósticas na evolução da infecção pelo HIV, sendo uma medida direta de imunocompetência celular, e, portanto, muito útil no acompanhamento de pacientes infectados pelo HIV.

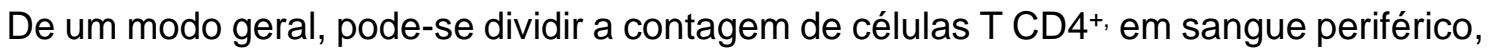
em quatro faixas: 1) TCD4+> 500 células $/ \mathrm{mm}^{3}$ : estágio da infecção pelo HIV com baixo risco de doença; 2) TCD4+ entre 200 e 500 células $/ \mathrm{mm}^{3}$; estágio frequentemente caracterizado pelo surgimento de sinais e sintomas menores ou alterações constitucionais, embora um contingente significativo de pacientes possa se manter assintomático; 3) TCD4+ entre 50 e 200 células $/ \mathrm{mm}^{3}$ : estágio com alta probabilidade de 
surgimento de doenças oportunistas indicativas de imunodeficiência de moderada à grave, como pneumocistose e toxoplasmose; 4) $\mathrm{TCD}^{+}<50$ células $/ \mathrm{mm}^{3}$ : estágio com grave comprometimento de resposta imunitária (BRASIL, 2002).

Desde o início da epidemia da AIDS, nos anos 1980 até hoje, muito tem sido feito para proporcionar melhor qualidade de vida aos portadores do HIV e, dentre outras ações, está a distribuição universal de medicamentos, ressaltando-se que o Brasil foi o primeiro país do terceiro mundo a adotar tal medida (COLOMBRINI; MORAES LOPES; FIGUEIREDO, 2006). A introdução da TARV propiciou grandes avanços no tratamento da AIDS, com dramática redução da morbidade e da mortalidade associadas à doença AIDS (ARAUJO, 2015).

São padronizadas, no Brasil, seis classes terapêuticas de ARV disponíveis por lei desde 1996 e garantidos a todas as pessoas soro positivas, são elas: Inibidor da Transcriptase Reversa Análogo de Nucleosídeo (ITRN) ou Nucleotídeo (ITRNt); Inibidor da Transcriptase Reversa Não Análogo de Nucleosídeo (ITRNN); Inibidor de Protease (IP) e Inibidor de Fusão (Isf). Em 2007, lançou-se, no mercado farmacêutico, o Maraviroque (MVQ) da classe dos Inibidores de Co-receptores (ICR) e, consequentemente, em 2008, inclui-se o Inibidor da Integrase (ININT) (RESENDE et al., 2013).

A classe terapêutica dos ITRN, bem como os ITRNt atuam quando a célula já foi infectada pelo vírus, ou seja, atuam na conversão do RNA viral em DNA (GONÇALVES, 2014). A principal vantagem dos ITRNN sobre os ITRN é que não necessitam de uma etapa inicial de ativação intracelular, fosforilação. Os ITRNN não interagem com o sítio ativo da Transcriptase Reversa, mas sim com um sítio de ligação alostérico, bloqueando, diretamente, a ação da enzima e a multiplicação do vírus (SOCIEDADE BRASILEIRA DE INFECTOLOGIA, 2005).

Os IP são fármacos que atuam no último estágio da replicação do vírus, impedindo que uma nova partícula viral seja formada (MELLO; REIS; RIBEIRO, 2008). Os ININT inibem uma enzima que promove a integração do DNA viral no código genético da célula hospedeira (MELLO; REIS; RIBEIRO, 2008). Os IsF são, atualmente, uma promissora estratégia no combate da replicação viral, na prevenção da entrada do vírus HIV, na célula hospedeira. Os IsF foram concebidos para atuar de maneira diferente dos medicamentos atuais, apresentando uma grande vantagem, já que são capazes de impedir que o vírus consiga penetrar nos linfócitos e nem sequer inicie a infecção, impedindo, assim, a replicação viral (SOUZA, 2005). 
Os ICR foram lançados no mercado farmacêutico em 2007, o chamado Maraviroque (MVQ), atuando por meio de um novo mecanismo de ação e o primeiro antagonista de receptores CCR5. Com esse mecanismo de ação inovador, os antagonistas de CCR5 têm como alvo os receptores de quimiocina CCR5, presentes nos linfócitos T, as principais células do hospedeiro infectadas pelo HIV. As quimiocinas exercem um papel chave na patogênese da AIDS, induzindo o extravasamento de leucócitos e orientando a sua migração para sítios de lesão tecidual (MIRANDA et al., 2010).

Pensando nessas questões, a pesquisa objetivou investigar o papel dos medicamentos no controle da CV e na contagem de células TCD4+ por meio da análise dos resultados dos exames (laudos) e correlacionar o período do início da medicação com a contagem de células TCD4+ e CV.

\section{METODOLOGIA}

O planejamento amostral desta pesquisa de natureza aplicada efetuou-se considerando os pacientes atendidos pela Vigilância Epidemiológica de uma cidade no meio oeste de Santa Catarina, com uma população estimada de 16.800 habitantes, dos quais 20, no ano de 2015, eram portadores de HIV/AIDS.

De um modo geral, pode-se dividir a contagem de células T CD4+ em sangue periférico, em quatro faixas: 1) $\mathrm{TCD}^{+}>500$ células $/ \mathrm{mm}^{3}$ (baixo risco de doença); 2) TCD4+ entre 200 e 500 células $/ \mathrm{mm}^{3}$ (surgimento de sinais e sintomas); 3) TCD4+ entre 50 e 200 células $/ \mathrm{mm}^{3}$ (surgimento de doenças oportunistas); 4) TCD4+ 50 células $/ \mathrm{mm}^{3}$ (estágio com grave comprometimento de resposta imunitária) (BRASIL, 2002).

Os critérios de inclusão foram os laudos com resultados de análises laboratoriais como contagem de células TCD4+ e CV no período entre 2011 e 2014. Os critérios de exclusão foram laudos de pacientes menores de idade e pacientes cadastrados que foram a óbito ou que tiveram exames incompletos, sendo assim o número total de prontuários de acompanhamento analisados foram 10.

Os resultados obtidos foram interpretados e classificados através de tabelas com exposição dos dados coletados: idade, sexo e interpretação dos resultados dos exames e medicamentos utilizados.

A pesquisa fora autorizada por autoridades dos órgãos de saúde local. Os nomes dos pacientes não se citaram neste estudo, cumprindo assim as exigências éticas. Este estudo foi submetido e aprovado pelo Comitê de Ética em Pesquisa com Seres Humanos da UNIARP, recebendo parecer favorável de número 1.173 .872 de 06/08/2015. 


\section{RESULTADOS E DISCUSSÕES}

Durante o período de estudo, analisaram-se 10 laudos. As características sociodemográficas mostraram predominância do sexo feminino com $70 \%(n=7)$ em relação ao sexo masculino com $30 \%(n=3)$, referente à idade $60 \%(n=6)$ dos prontuários analisados, apresentaram idade entre 38 a 48 anos e $40 \%(n=4)$ de 27 a 37 anos.

Desde seu início, o cenário epidêmico HIV/AIDS sofreu muitas mudanças em se considerando os níveis mundiais, o que reflete em alterações de perfis epidemiológicos de pessoas convivendo com o vírus e/ou a doença. Nos primeiros anos, os coeficientes de incidência apontavam para o sexo masculino como maior população afetada pelo vírus, bem como a patologia, entretanto, embora mais indivíduos do sexo masculino sejam notificados no Brasil, a velocidade de crescimento da epidemia é maior entre as mulheres, sendo que nessas o vírus apresenta índices de infecção até $40 \%$ superiores aos verificados em homens. Aproximadamente, $43 \%$ das mulheres infectadas estão em fase reprodutiva em todo o mundo, o que define o risco de crescimento da transmissão vertical do HIV (VON MUHLEN; SALDANHA; STREY, 2014).

O Quadro 1 representa os resultados dos exames obtidos por meio deste estudo, nos anos de 2011 a 2014, caracterizados pela contagem da CV e de células TCD4+.

Quadro 1. Distribuição dos resultados de CV e contagem de células TCD4+

\begin{tabular}{|c|c|c|c|c|c|c|c|c|}
\hline Laudo & \multicolumn{3}{|c|}{ Carga Viral - cópias/mL } & \multicolumn{3}{c|}{ TCD4 $^{+} / \mathbf{m m}^{3}$} \\
\hline & 2011 & 2012 & 2013 & 2014 & 2011 & 2012 & 2013 & 2014 \\
\hline $\mathbf{1}$ & $<50$ & $<50$ & 50.127 & 20.033 & 591 & 912 & 536 & 612 \\
\hline $\mathbf{2}$ & 6.325 & 5.600 & 5.004 & 8.839 & 607 & 466 & 626 & 500 \\
\hline $\mathbf{3}$ & 43.846 & 40.743 & 253.728 & $\star$ & 406 & 370 & 274 & ${ }^{*}$ \\
\hline $\mathbf{4}$ & $<50$ & $<50$ & $\mathrm{ND}$ & $\mathrm{ND}$ & 497 & 460 & 463 & 547 \\
\hline $\mathbf{5}$ & $<50$ & $<50$ & $\mathrm{ND}$ & $\mathrm{ND}$ & 1.113 & 1.612 & 1.864 & ${ }^{*}$ \\
\hline $\mathbf{6}$ & $<50$ & $<50$ & $\mathrm{ND}$ & $\mathrm{ND}$ & 704 & 712 & 700 & ${ }^{*}$ \\
\hline $\mathbf{7}$ & $<50$ & $<50$ & $\mathrm{ND}$ & $<50$ & 567 & 877 & 949 & 1.185 \\
\hline $\mathbf{8}$ & $<50$ & $<50$ & $<50$ & $\mathrm{ND}$ & 704 & 712 & 619 & 580 \\
\hline $\mathbf{9}$ & 522 & 958 & 1.733 & 1.193 & 590 & 377 & 355 & 392 \\
\hline $\mathbf{1 0}$ & $\star$ & $\star$ & 1.384 .631 & 77 & ${ }^{*}$ & ${ }^{*}$ & 56 & 253 \\
\hline
\end{tabular}

ND: Não detectável

*: Dosagem não realizada

Para que os resultados satisfatórios sejam obtidos, a adesão ao tratamento deve ser muito bem trabalhada, pois o paciente que estiver com os níveis adequados de células TCD4 ${ }^{+}$, possivelmente, não vai sentir nenhum efeito benéfico do tratamento, pelo contrário, pode até mesmo apresentar efeitos adversos, o que pode resultar na não adesão ao tratamento, e, possivelmente, uma resistência viral, fazendo com que seja necessária a troca do esquema de primeira escolha por esquemas mais complexos. 
No laudo 1, observa-se uma oscilação correspondente aos anos de 2013 e 2014, havendo, no ano de 2013, um aumento significativo da CV e uma queda brusca das células $\mathrm{TCD}^{+}$, considerando a hipótese de que o paciente não tenha aderido com efetividade a TARV. Já, no ano de 2014, como o esperado, ao retomar o tratamento, o paciente apresentou uma melhora nos níveis da CV e, consequentemente, aumento das células TCD4+.

Os resultados dos exames nos laudos 2 e 9 evidenciam um tratamento de forma incorreta. Quando analisamos os prontuários, observou-se que as razões para não tomarem seus medicamentos foi por causa da grande quantidade de medicamentos $e$ dos efeitos colaterais. Romeu (2012) observou que $98,3 \%$ dos pacientes deixaram de tomar alguma vez o medicamento por se sentiram melhor ou por sentirem-se triste/deprimido. Enquanto que $96,6 \%$ relataram ter deixado alguma vez de tomar por sentir-se pior.

Em relação ao paciente 3, que relata etilismo, acredita-se que não tenha aderido ao tratamento, pois não apresentou nenhum tipo de melhora, comparado aos demais que se integraram à terapia farmacológica.

Dentre os laudos analisados, pode-se perceber uma correlação positiva e significativa nos pacientes $4,5,6,7$ e 8, entre a redução da CV e a TARV, na qual o objetivo dos medicamentos seria exatamente esse, resultando em uma CV não detectável, ou seja, <50 cópias/ml. É importante considerar que os pacientes devem seguir um tratamento correto, cumprindo os horários prescritos e não abandonem para que possa haver essa correlação positiva, como citado acima.

No laudo 10, sabe-se que a paciente procurou um médico, fora, então, solicitado exames, sendo assim diagnosticada como soro positiva, estando, visualmente, debilitada e já apresentando características do herpes zoster, exames positivos para sífilis, toxoplasmose e candidíase oral, caracterizando um sistema imunológico debilitado. Após cinco meses de tratamento, a paciente apresentou ganho de peso e significativa melhora na contagem de células TCD4 ${ }^{+}$e redução expressiva na CV.

O segundo quadro relata os medicamentos que os pacientes do presente estudo utilizam e suas respectivas posologias.

O aumento dos linfócitos TCD4+, para valores acima de 350 células $/ \mathrm{mm}^{3}$, afastam as chances de infecções oportunistas que são as principais causas que debilitam o organismo dos portadores e fazem surgir o conjunto de sinais e sintomas característicos da AIDS (BRITO; CASTILHO; SZWARCWALD, 2000).

Entre os portadores que realizam o tratamento, a maioria apresentou CV abaixo do limite mínimo e contagem de linfócitos TCD4+ acima de 350 células $/ \mathrm{mm}^{3}$, demonstrando o efeito positivo da terapêutica em reduzir as chances de desenvolvimento de infecções oportunistas. 
Evidências demonstram o benefício da TARV em pessoas com AIDS ou outros sintomas relacionados à imunodeficiência provocada pelo HIV e em indivíduos assintomáticos com contagem de TCD4+ inferior a 350 células $/ \mathrm{mm}^{3}$ (SEIDL; ZANNON; TRÓCCOLI, 2005; FIZAZZO, 2012).

Quadro 2. Medicamentos utilizados pelos participantes da pesquisa.

\begin{tabular}{|c|c|c|c|}
\hline Paciente & Medicamento & & Posologia \\
\hline 1 & $\begin{array}{c}\text { Zidovudina 300mg + Lamivudina 150mg e } \\
\text { Nevirapina 200mg }\end{array}$ & $\begin{array}{l}1 \\
1\end{array}$ & $\begin{array}{l}\text { Comprimido } 2 \times \text { ao dia } \\
\text { Comprimido } 2 \times \text { ao dia }\end{array}$ \\
\hline 2 & $\begin{array}{c}\text { Tenofovir 300mg + Lamivudina 300mg + } \\
\text { Efavirenz } 600 \mathrm{mg}(3 \mathrm{em} \mathrm{1)}\end{array}$ & 1 & Comprimido ao dia \\
\hline 3 & $\begin{array}{c}\text { Zidovudina 300mg + Lamivudina 150mg e } \\
\text { Efavirenz } 600 \mathrm{mg}\end{array}$ & $\begin{array}{l}1 \\
1\end{array}$ & $\begin{array}{l}\text { Comprimido } 2 \times \text { ao dia } \\
\text { Comprimido à noite }\end{array}$ \\
\hline 4 & $\begin{array}{c}\text { Zidovudina 300mg + Lamivudina 150mg e } \\
\text { Efavirenz 600mg }\end{array}$ & $\begin{array}{l}1 \\
1\end{array}$ & $\begin{array}{l}\text { Comprimido } 2 \times \text { ao dia } \\
\text { Comprimido à noite }\end{array}$ \\
\hline 5 & $\begin{array}{c}\text { Zidovudina 300mg + Lamivudina 150mg e } \\
\text { Ritonavir100mg e } \\
\text { Atazanavir } 300 \mathrm{mg}\end{array}$ & $\begin{array}{l}1 \\
1 \\
1\end{array}$ & $\begin{array}{l}\text { Comprimido } 2 \times \text { ao dia } \\
\text { Comprimido ao dia } \\
\text { Comprimido ao dia }\end{array}$ \\
\hline 6 & $\begin{array}{c}\text { Zidovudina 300mg + Lamivudina 150mg e } \\
\text { Nevirapina 200mg }\end{array}$ & $\begin{array}{l}1 \\
1\end{array}$ & $\begin{array}{l}\text { Comprimido } 2 \times \text { ao dia } \\
\text { Comprimido } 2 \times \text { ao dia }\end{array}$ \\
\hline 7 & $\begin{array}{c}\text { Zidovudina } 300 \mathrm{mg}+\text { Lamivudina } 150 \mathrm{mg} \text { e } \\
\text { Lopinavir } 200 \mathrm{mg} \text { + Ritonavir } 50 \mathrm{mg}\end{array}$ & $\begin{array}{l}1 \\
1\end{array}$ & $\begin{array}{l}\text { Comprimido } 2 \times \text { ao dia } \\
\text { Comprimido } 2 \times \text { ao dia }\end{array}$ \\
\hline 8 & $\begin{array}{c}\text { Zidovudina 300mg + Lamivudina 150mg e } \\
\text { Nevirapina 200mg }\end{array}$ & $\begin{array}{l}1 \\
1\end{array}$ & $\begin{array}{l}\text { Comprimido } 2 \times \text { ao dia } \\
\text { Comprimido } 2 \times \text { ao dia }\end{array}$ \\
\hline 9 & $\begin{array}{c}\text { Tenofovir 300mg + Lamivudina 300mg + } \\
\text { Efavirenz } 600 \mathrm{mg}(3 \mathrm{em} \mathrm{1)}\end{array}$ & 1 & Comprimido ao dia \\
\hline 10 & $\begin{array}{c}\text { Tenofovir 300mg + Lamivudina 300mg + } \\
\text { Efavirenz 600mg (3 em 1) }\end{array}$ & 1 & Comprimido ao dia \\
\hline
\end{tabular}

Dentre os pacientes acompanhados, os ARV prescritos, o Biovir ${ }^{\circledR}$ (Zidovudina e Lamivudina) apresentou-se como o mais prescrito (70\%), da classe dos (ITRN) e o mesmo obteve $50 \%$ de associações com a classe dos ITRNN, e $20 \%$ entre associações de IP, seguido pelo Tenofovir + Lamivudina + Efavirenz (30\%) e das associações das classes ITRNt, ITRN e ITRNN.

Desde o início da epidemia de AIDS no Brasil, em 1980 até junho de 2015, registraram-se, no país, 798.366 casos de AIDS, 41.324 a mais que no ano de 2014. As regiões Sul e Centro-Oeste possuem maior proporção de casos oriundos do Sinan que no Norte, Nordeste e Sudeste. No Brasil, desde 1980 até junho de 2015, 519.183 (65\%) casos de AIDS atingem os homens e 278.960 (35\%) casos estão registrados entre as mulheres, sendo que o número de mortes relacionadas à AIDS, no Brasil, foi de 16.000 [ \pm 7.000], em 2014 (BRASIL, 2015).

A taxa de detecção de AIDS no Brasil tem apresentado estabilização nos últimos dez anos, com uma média de 20,5 casos para cada 100 mil habitantes. Em relação à região Sul, também, houve uma estabilidade no número de casos com uma taxa de detecção de 31,1 casos para cada 100 mil habitantes (BRASIL, 2015).

O tempo de sobrevida do paciente HIV/AIDS aumentou após o início e avanços da TARV. O objetivo de inibir a replicação do HIV pelo uso dos fármacos proporciona 
uma elevação da contagem de $\mathrm{CD}^{+}{ }^{+}$e diminuição da carga viral devido à redução do RNA viral. A TARV combinada pode aumentar a supressão viral, prevenir a resistência aos fármacos e simplificar a posologia, sendo, atualmente, composta por associações de fármacos. O uso de vários medicamentos em diferentes horas do dia diminui a adesão pelos portadores do HIV ao tratamento. A associação de medicamentos é uma tentativa de diminuir os erros e o abandono durante o tratamento (FERREIRA; OLIVEIRA; PANIAGO, 2012).

Segundo Sousa (2014), a CV está associada à transmissão do HIV. O acompanhamento da CV com intervenção adequada no sentido de diminuí-la pode constituir uma das estratégias para a quebra na cadeia de transmissão. Justamente por esse motivo, o Ministério da Saúde implantou o Novo Protocolo Clínico de Tratamento de Adultos com HIV/AIDS, para que todos os indivíduos sejam tratados independentemente da CV células $\mathrm{TCD}^{+}$, na perspectiva de redução da transmissibilidade do HIV.

Entre 2005 e 2014, o Ministério da Saúde mais do que dobrou o total de pacientes soropositivos com acesso ao tratamento com ARV no país, passando de 165 mil (2005) para 400 mil (2014). Atualmente, o SUS oferece, gratuitamente, 22 medicamentos para os pacientes com HIV/AIDS Desse total, 12 são produzidos no Brasil (BRASIL, 2015).

O comportamento epidêmico do HIV/AIDS no Brasil não se apresenta heterogêneo quando taxas de incidências, grupos populacionais e índices de sobrevivência são observados. A redução mais acentuada nos estados das regiões Sul e Sudeste, bem como os índices de sobrevivência pós-diagnóstico nessas regiões é discrepante do resto do país. Sendo assim, pode-se descrever essa epidemia como um conjunto de várias subepidemias consequentes das diferenças entre perfis socioculturais e dos graus de investimento na saúde (FERREIRA; OLIVEIRA; PANIAGO, 2012).

\section{CONCLUSÃO}

É fundamental que os profissionais de saúde estejam preparados para identificar os principais fatores de riscos para a não adesão e, assim, propor intervenções que, efetivamente, viabilizem a promoção da adesão ao paciente para o tratamento proposto. Ainda há muito que se fazer. De uma forma geral, o principal desafio a ser vencido é de que as pessoas se conscientizem sobre a importância do tratamento, melhorando a qualidade e a expectativa de vida.

Este estudo encontrou uma correlação positiva entre as pessoas em uso da TARV e que mantêm contagens de TCD4+ acima de 500 células $/ \mathrm{mm}^{3}$ e CV indetectável. Essas pessoas atingem expectativa de vida semelhante à da população em geral, ou seja, os medicamentos ARV são eficazes sim, desde que sejam administrados adequadamente 
e que os pacientes sigam um tratamento correto. O presente estudo salienta que a carga viral é um excelente recurso para avaliar a eficácia terapêutica.

\section{REFERÊNCIAS}

ARAÚJO, J.I.R. Desenvolvimento de método indicativo de estabilidade para detecção de produtos de degradação da associação de zidovudina e lamivudina (300+150 $\mathbf{~ m g}$ ) em matéria-prima e comprimidos. 2015. 109 f. Monografia (Bacharelado em Farmácia). Curso de Farmácia - Universidade Federal da Paraíba; 2015.

BRASIL. Ministério da Saúde. Boletim Epidemiológico Aids e DST. v. 4, n.1. Brasília; 2015.

BRASIL. Ministério Da Saúde. Instituto Nacional do Seguro Social. Norma técnica de avaliação da incapacidade laborativa para fins de benefícios previdenciários em HIV/AIDS. Resolução INSS/DC n. 089, 05 abril 2002. Brasília; 2002.

BRASIL. Ministério da Saúde. Prevenção - Uso de medicamentos pós-exposição ao HIV terá protocolo. Brasília; 2015.

BRITO, A.M; CASTILHO, E.A; SZWARCWALD, C.L. AIDS e infecção pelo HIV no Brasil: uma epidemia multifacetada. Revista da Sociedade Brasileira de Medicina Tropical, v. 34, n. 2, p. 207-217, 2000.

COLOMBRINI, M.R.C; MORAES LOPES, M.H.B; FIGUEIREDO, R.M. Adesão à terapia antiretroviral para HIV/AIDS. Revista da Escola de Enfermagem da USP. v.40, n. 4, p. 576-581, 2006.

FERREIRA, BE; OLIVEIRA, IM; PANIAGO, AMM. Qualidade de vida de portadores de HIV/AIDS e sua relação com linfócitos $\mathrm{CD}^{+}$, carga viral e tempo de diagnóstico. Revista Brasileira de Epidemiologia, v.15, n. 1, p. 75-84, 2012.

FINAZZO, C. Geração in vitro de células T efetoras e células T reguladoras mediadas por células dendríticas pulsadas com vírus autólogo de pacientes infectados pelo HIV-1. 2012. 115 f. Tese (Doutorado). Universidade de São Paulo; 2012.

GONÇALVES, J.C. Análise comparativa de protocolos de terapia medicamentosa em pessoas adultas vivendo com HIV/AIDS. 2014. $52 \mathrm{f}$. Monografia (Bacharelado em Farmácia). Universidade de Brasília; 2014.

MELLO, A.R.M; REIS, E.M; RIBEIRO, R.L Lipodistrofia no uso da terapia antirretroviral com inibidores da protease no HIV. Saúde \& Ambiente em Revista. v.3, n. 1, p. 0675, 2008.

MIRANDA, A. S, et al. Maraviroque: uma inovação terapêutica para o tratamento da AIDS. Revista Virtual de Química, v.2, n. 2, p. 130-139, 2010.

RESENDE, RC, et al. Adesão ao tratamento antirretroviral de pacientes vivendo com HIV/AIDS atendidos pelo Sistema Único de Saúde. Revista da Universidade Vale do Rio Verde. v. 10, n. 2, p. 186-201, 2013. 
ROMEU, G.A. Avaliação da Adesão a Terapia Antirretroviral de Pacientes portadores de HIV. Revista Brasileira Farmácia Hospitalar e Serviços de Saúde, v.3, n.1, p. 37-41, 2012.

SEIDL, E.M.F; ZANNON, C.M.L.C; TRÓCCOLI, B.T. Pessoas vivendo com HIV/AIDS: enfrentamento, suporte social e qualidade de vida. Psicologia: Reflexão e crítica, v. 18, n. 2, p. 188-195, 2005.

SILVA, M.M. Polimorfismo da região do fator de necrose tumoral (TNF) na síndrome da lipodistrofia associada à terapia anti-retroviral em portadores do HIV-1. 155 f. Dissertação (Mestrado). Escola de Enfermagem de Ribeirão Preto. Universidade de São Paulo; 2008.

SOCIEDADE BRASILEIRA DE INFECTOLOGIA. Terapia antirretroviral e alterações metabólicas, 2005. Disponível em: <http://www.infectologia.org.br/wpcontent/uploads/2015/04/Infecto-Hoje-01.pdf>. Acesso em: 16 jul. 2015.

SOUSA, A. I. A. Uso da carga viral e de técnicas de georreferenciamento como contribuição para o monitoramento da transmissão de HIV/AIDS no Brasil, 1996 a 2011.2014. 88 f. Dissertação (Mestrado). Núcleo de Medicina. Universidade de Brasília; 2014.

SOUZA, M. V. N. Fármacos inibidores de fusão: uma nova estratégia no combate à replicação do vírus VIH. Acta Farmacêutica Bonaerense, v. 24, n.2, p. 291-299, 2005.

VON MUHLEN, BK; SALDANHA, M; STREY, MN. Mulheres e o HIV/AIDS: Intersecções Entre Gênero, Feminismo, Psicologia e Saúde Pública. Revista Colombiana de Psicologia, v.23, n.2, p. 285-296, 2014. 